\title{
An Antidote Screening System for Organophosphorus Poisoning using Zebrafish Larvae
}

Leslie E. Dubrana1, Anja Knoll-Gellida ${ }^{1}$, Laure M. Bourcier ${ }^{1}$, Théo Mercé1, Sandra Pedemay $^{1}$, Florian Nachon², André-Guilhem Calas ${ }^{2}$, Rachid Baati ${ }^{3}$, Magalie Soares ${ }^{1}$ and Patrick J. Babin ${ }^{1 *}$

${ }^{1}$ Department of Life and Health Sciences, INSERM, Maladies Rares: Génétique et Métabolisme (MRGM), U1211, Université de Bordeaux, F-33615 Pessac, France.

${ }^{2}$ Département de Toxicologie et Risques Chimiques, Institut de Recherche Biomédicale des Armés, F-91220 Brétigny sur Orge, France.

${ }^{3}$ ECPM UMR CNRS 7515, ICPEES Institut de Chimie et Procédés pour l’Énergie, l’Environnement et la Santé, F-67087 Strasbourg, France.

Patrick J. Babin: ORCID ID: 0000-0002-7411-2297

*To whom correspondence should be addressed at: Laboratoire Maladies Rares : Génétique et Métabolisme (MRGM), INSERM U1211, Université de Bordeaux, Allée Geoffroy St-Hilaire, Bat. B2, 2ème étage, CS 50023, 33615 Pessac cedex, France.

E-mail: patrick.babin@u-bordeaux.fr 


\section{Supplementary Figures}
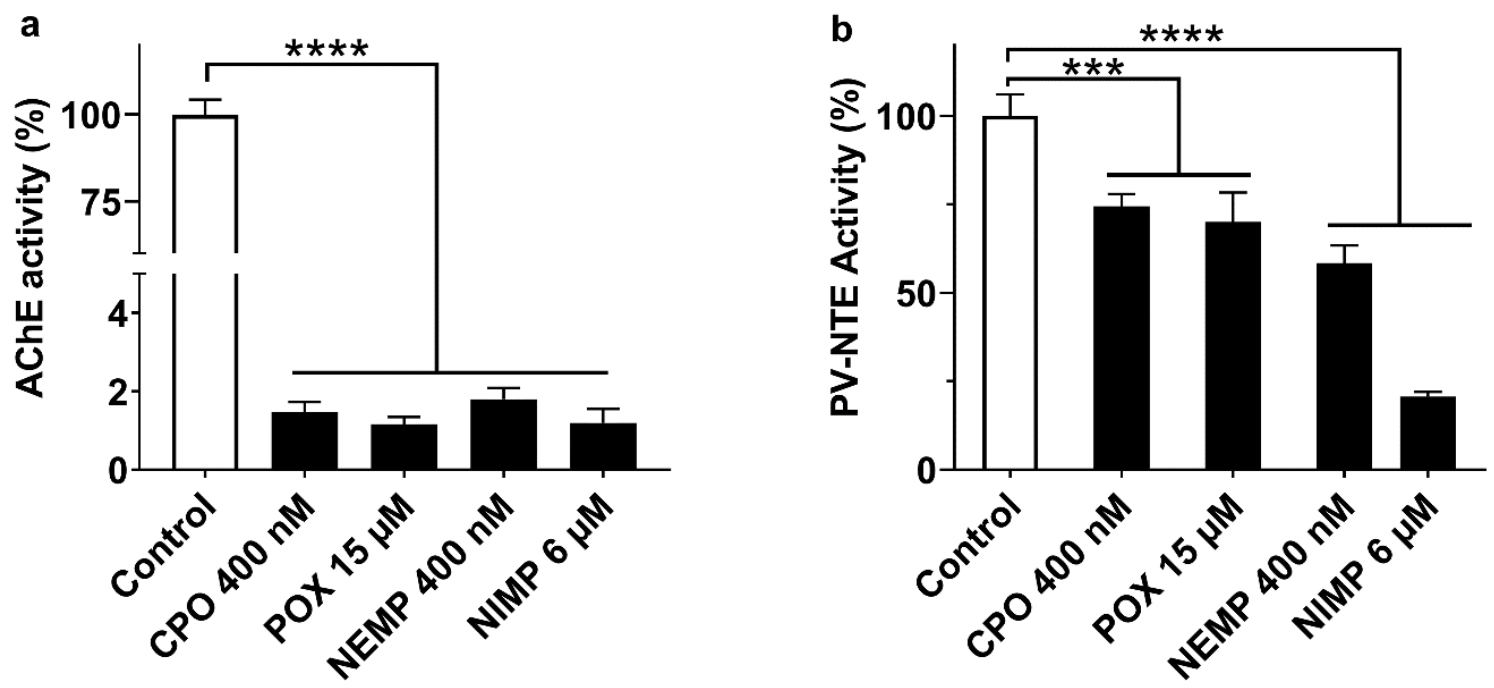

Figure S1. AChE and PV-NTE residual activities at the working concentrations used according to the OP chosen. a,b, Inhibition of AChE (a) or NTE (b) activity by the defined working concentrations of OPs, i.e. CPO 400 nM, POX $15 \mu \mathrm{M}$, NEMP $400 \mathrm{nM}$ and NIMP 6 $\mu \mathrm{M}$ in the presence of DMSO $0.1 \%$ (control) after $1 \mathrm{~h}$ of exposure. For the $7 \mathrm{dpf}$ larvae, $100 \%$ AChE activity was $1.35 \pm 0.06 \mu \mathrm{M} / \mu \mathrm{g}$ of protein/min and $100 \%$ NTE activity was $35.8 \pm 5.7$ $\mathrm{mM} / \mathrm{g}$ of protein/min. The data shown represent thirty-two independent experiments for the control group and twelve to fifteen independent experiments for the OP treated group in the AChE assays. The data shown represent twelve independent experiments for the control group and nine to twenty experiments for the OP treated groups. The significance was tested using a one-way ANOVA with Dunnett's post-hoc test, ***p $<0.001 ; * * * * \mathrm{p}<0.0001$. 


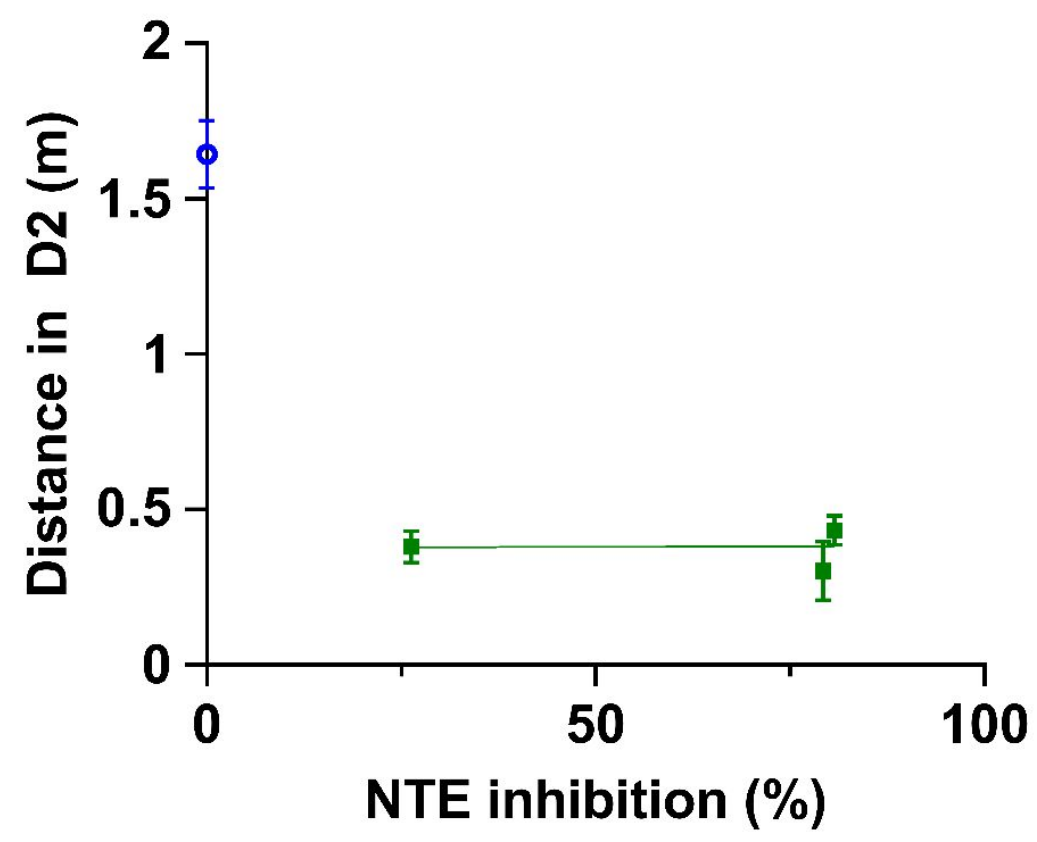

Figure S2. The distance travelled by NIMP treated larvae is not correlated with the inhibition of PV-NTE activity. The curves represent the total distance moved during the second dark phase D2 of the VMR protocol for three chosen NIMP concentrations: $100 \mathrm{nM}, 1$ $\mu \mathrm{M}$ and $6 \mu \mathrm{M}$ (green dots), corresponding to three different percentages of PV-NTE activity inhibition. The distance travelled in this phase by the control animals is represented by the blue point. These data correspond to the means \pm SEM obtained from twelve to eighteen larvae resulting from two to three independent experiments. The correlation was tested using Pearson's coefficient and was not statistically significant. 

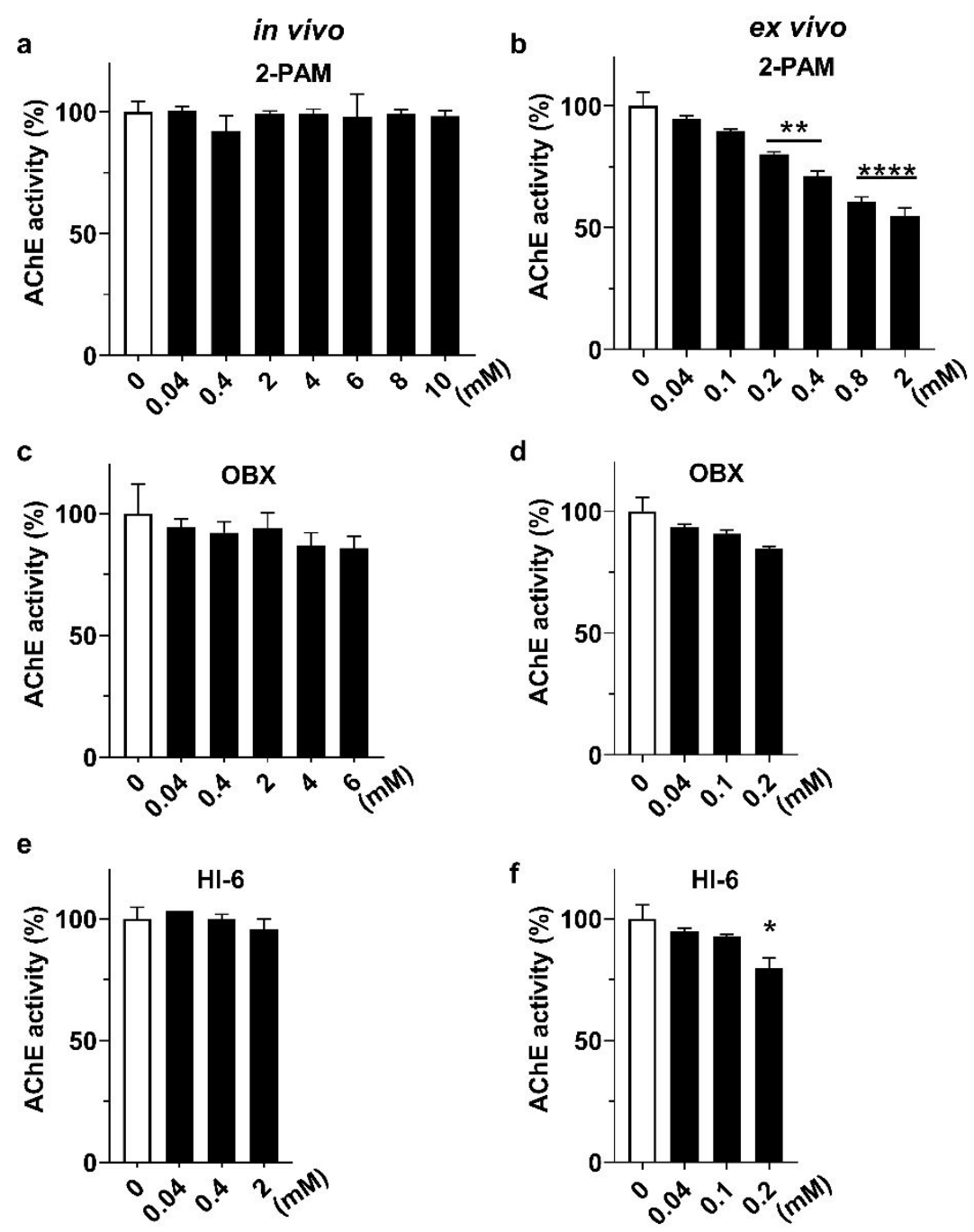

Figure S3. In vivo and ex vivo AChE activities for a concentration range of 2-PAM, OBX and HI-6. The oxime inhibitory potency of 2-PAM, OBX and HI-6 was investigated in vivo and ex vivo in the presence of $0.1 \%$ and $0.01 \%$ DMSO, respectively. a,c,e, The in vivo assay of $\mathrm{AChE}$ activity was done with a 0 to $10 \mathrm{mM}$ concentration range of 2-PAM (a, three to nine independent experiments), a 0 to $6 \mathrm{mM}$ concentration range of OBX (c, six independent experiments) and a 0 to $2 \mathrm{mM}$ concentration range of HI-6 (e, one to three independent experiments). b,d,f, The ex vivo assay of $\mathrm{AChE}$ activity reactivation was performed with a 0 to $2 \mathrm{mM}$ concentration range of 2-PAM (b, three to eight independent experiments) and a 0 to $0.2 \mathrm{mM}$ concentration range of OBX (d, six independent experiments) and HI-6 (f, six independent experiments). The control group values were obtained from twelve independent experiments. For all of these values, the data shown are the mean $\pm \mathrm{SEM}$ and the significances were tested using a one-way ANOVA and Dunnett's post-hoc test, ${ }^{*} \mathrm{p}<0.05$, $* * \mathrm{p}<0.01$ and $* * * * \mathrm{p}<0.0001$. 
a

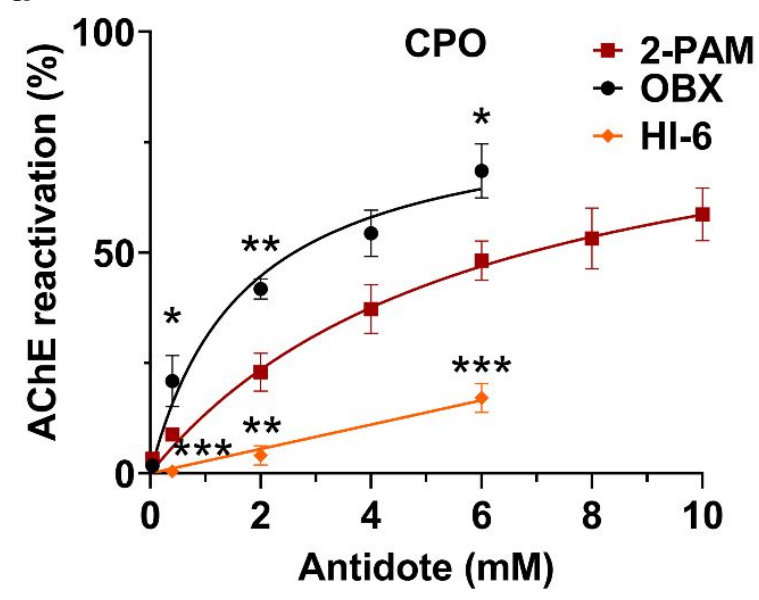

C

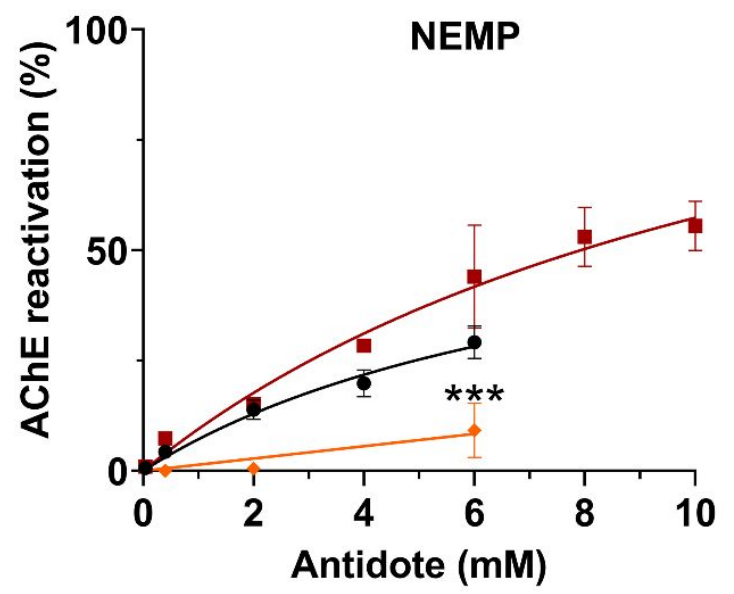

b

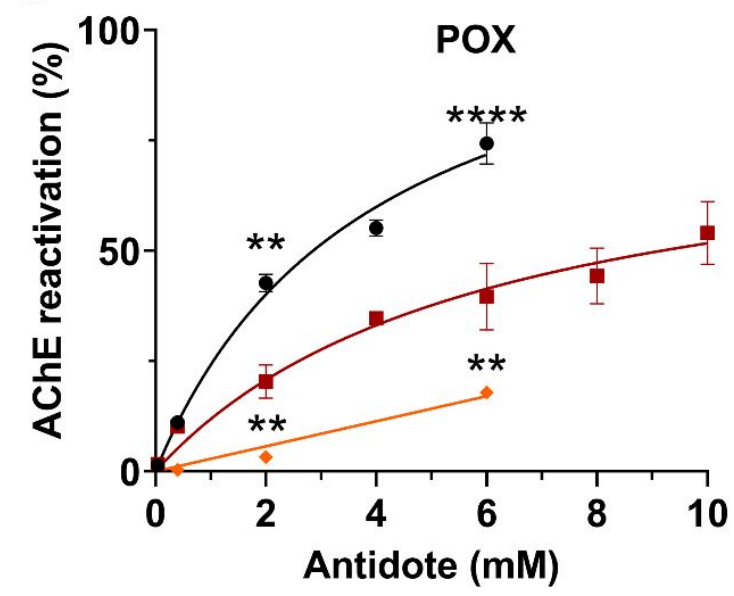

d

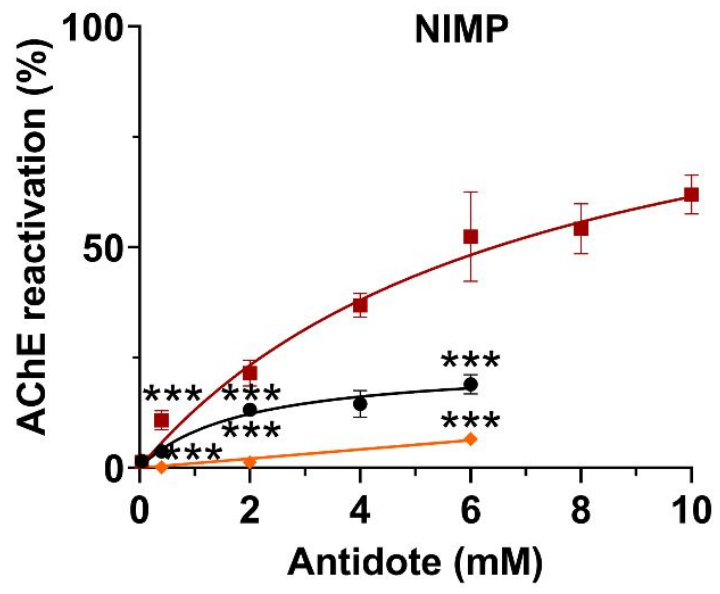

Figure S4. In vivo AChE activity reactivation of OP treated larvae exposed to increasing concentrations of selected oximes. The oxime efficacy of 2-PAM, OBX and HI-6 to reactivate $\mathrm{AChE}$ activity was investigated at the defined OP working concentrations in the larvae and given as the reactivation percentage for the CPO (a), POX (b), NEMP (c) and NIMP (d) treated groups. The AChE reactivation in vivo assay was performed with a 0 to 10 $\mathrm{mM}$ concentration range of 2-PAM (a, three to five independent experiments), and a 0 to 6 $\mathrm{mM}$ concentration range of $\mathrm{OBX}$ (b, three independent experiments) or HI-6 (c, one to three independent experiments). The curves were obtained with a hyperbola fit and the $\mathrm{R}^{2}$ values are given in the methods section. For all of the graphs, the data shown are the mean $\pm \mathrm{SEM}$. The significances were tested using a two-way ANOVA and Dunnett's post-hoc test, where OBX and HI-6 reactivation rates were compared to the 2-PAM rate, ${ }^{*} \mathrm{p}<0.05,{ }^{* *} \mathrm{p}<0.01$, $* * * \mathrm{p}<0.001, * * * * \mathrm{p}<0.0001$. 

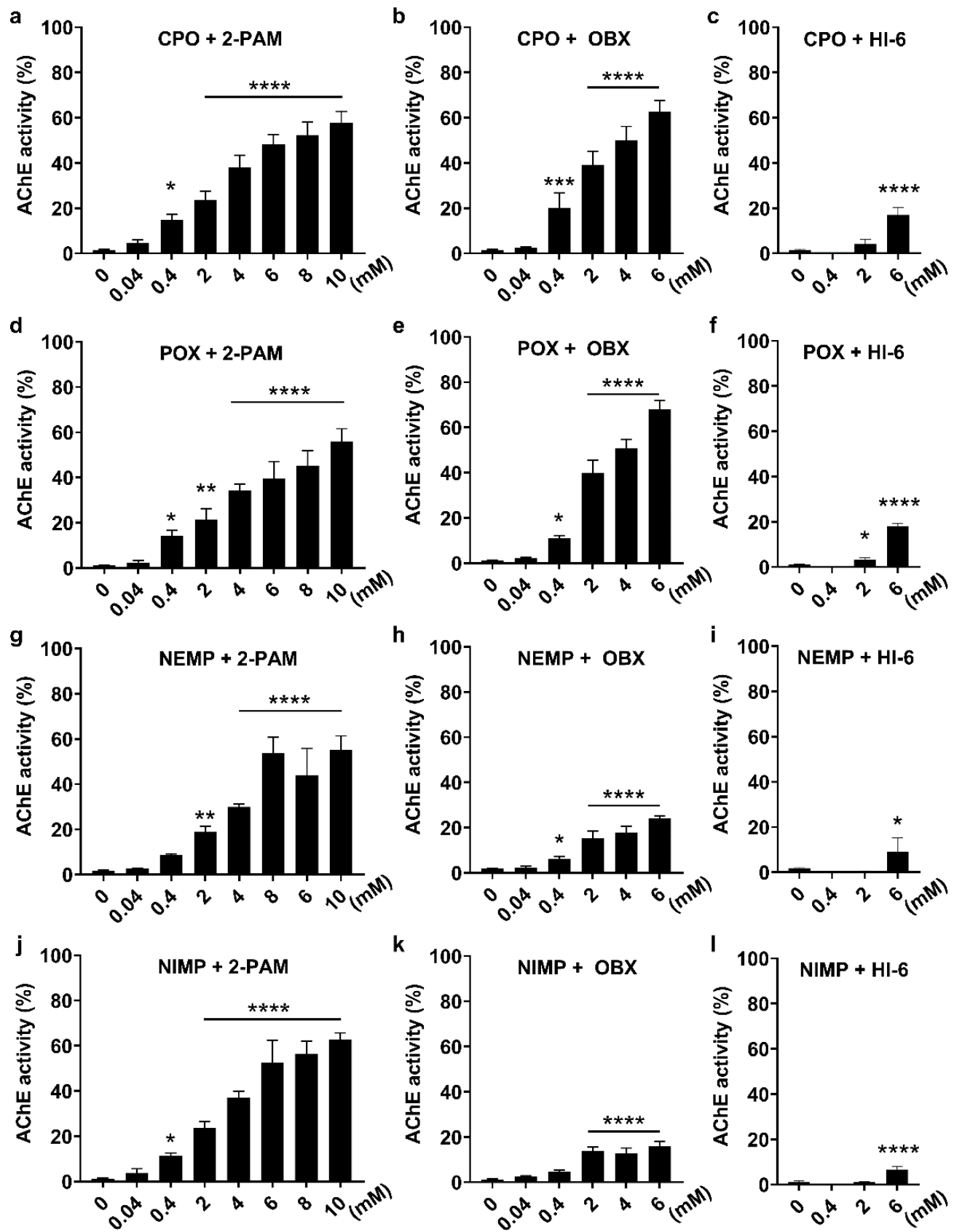

Figure S5. Determination of the minimum antidote concentration necessary to

significantly reactivate $\mathrm{AChE}$ in vivo after its inhibition by one of the selected OPs. At the defined OP working concentrations, the in vivo AChE activity was measured for CPO (ac), POX (d-f), NEMP (g-i) and NIMP (j-l) in the presence of a concentration range of 2-PAM, OBX or HI-6. The 2-PAM data are from three to five independent experiments, the OBX data are from three independent experiments and the HI-6 data are from one to three independent experiments. The data shown are the mean \pm SEM. The significances were tested using a oneway ANOVA and Dunnett's post-hoc test, and compared to the OP treated group, ${ }^{*} \mathrm{p}<0.05$, $* * \mathrm{p}<0.01, * * * \mathrm{p}<0.001, * * * * \mathrm{p}<0.0001$ 

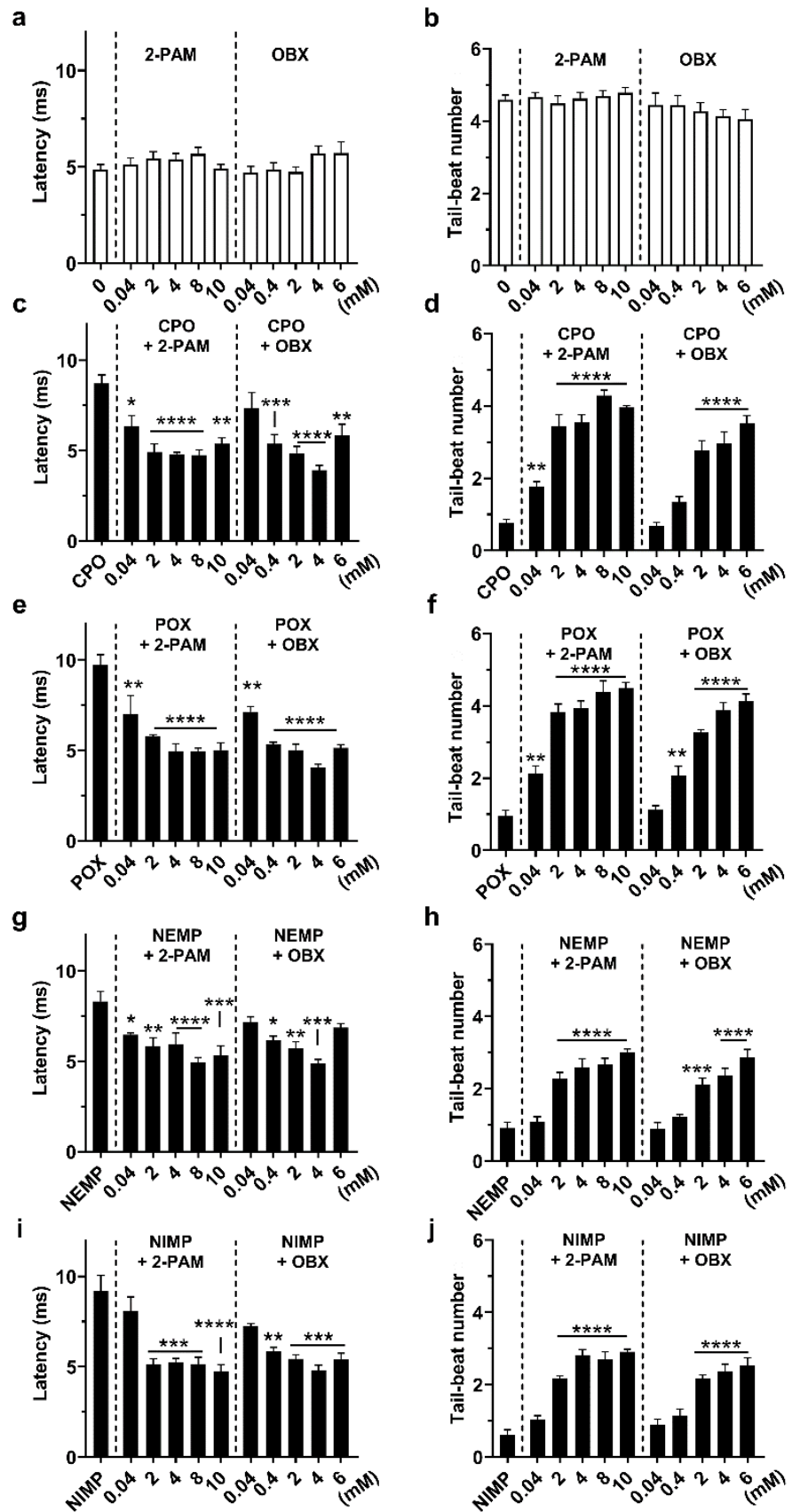

h

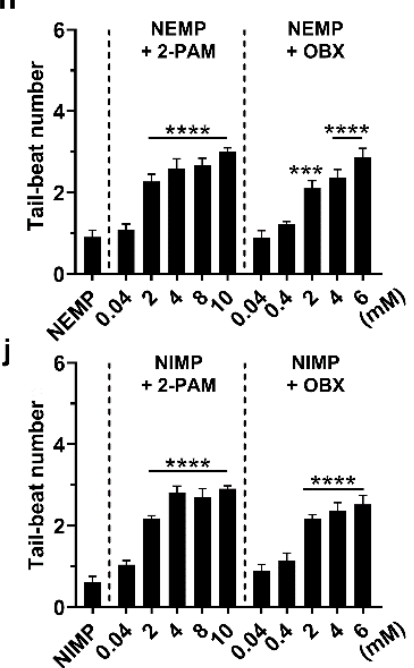

Figure S6. Determination of the minimum antidote concentration required to induce a significant reactivation for the latency and the tail-beat number measured in the EFPMR test. The latency time and tail-beat number in $100 \mathrm{~ms}$ by the larvae after EFP stimulation were measured at the end of $1 \mathrm{~h}$ of co-exposure. Both parameters are reported for the control $(\mathbf{a}, \mathbf{b}), \operatorname{CPO}(\mathbf{c}, \mathbf{d}), \operatorname{POX}(\mathbf{e}, \mathbf{f}), \operatorname{NEMP}(\mathbf{g}, \mathbf{h})$ and NIMP $(\mathbf{i}, \mathbf{j})$ groups in the presence of a concentration range of 2-PAM or OBX. Three independent experiments were performed with twelve larvae per group. The data shown are the mean \pm SEM. The significances were tested using a one-way ANOVA and Dunnett's post-hoc test and were compared to the OP condition, $* \mathrm{p}<0.05, * * \mathrm{p}<0.01, * * * \mathrm{p}<0.001, * * * * \mathrm{p}<0.0001$. 

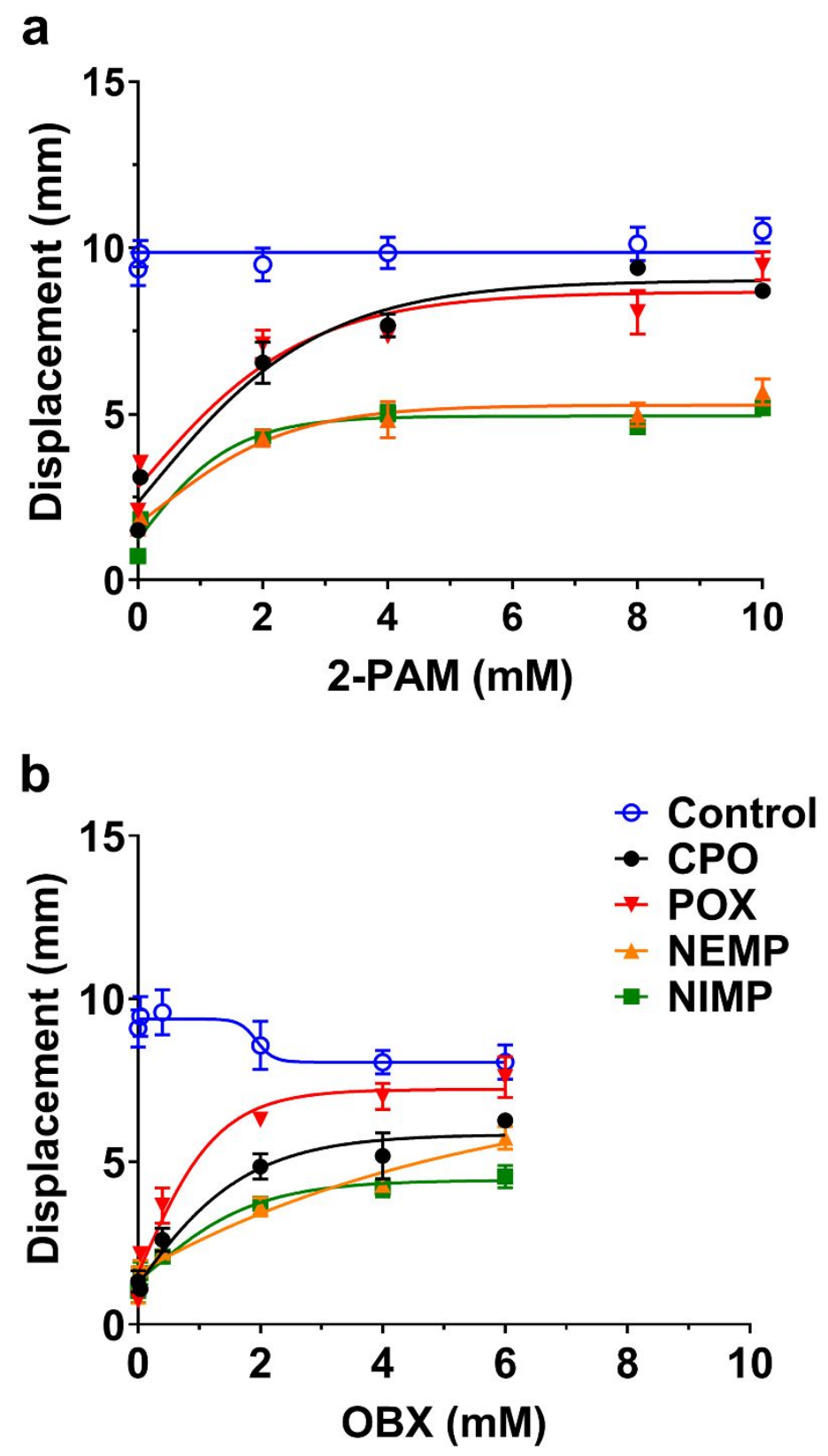

Figure S7. Assessment of the ability of an antidote to protect PNS functionality. Larvae displacement in $100 \mathrm{~ms}$ after EFP stimulation at the end of the OP exposure period in the presence of a concentration range of 2-PAM (a) or OBX (b). The data represent three independent experiments and contained twelve larvae per group. The curves were obtained with a hyperbola fit and the significance was tested using a two-way ANOVA (see Table S4 for statistical details). 

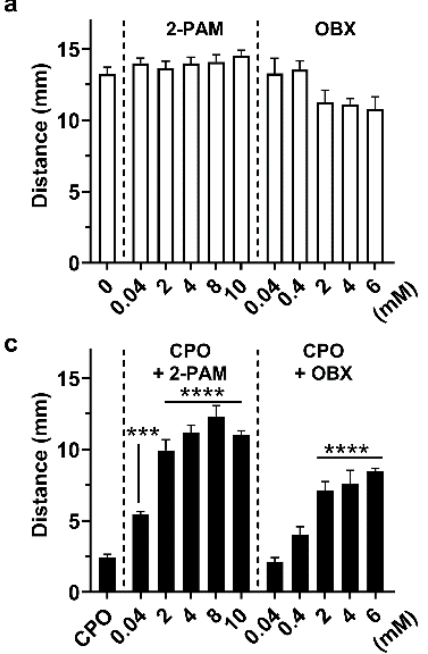

e

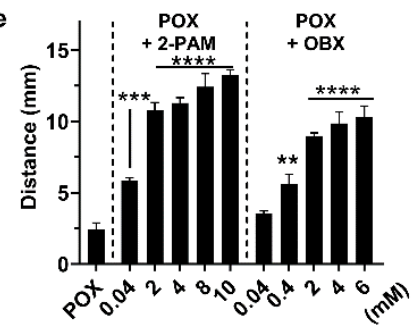

g
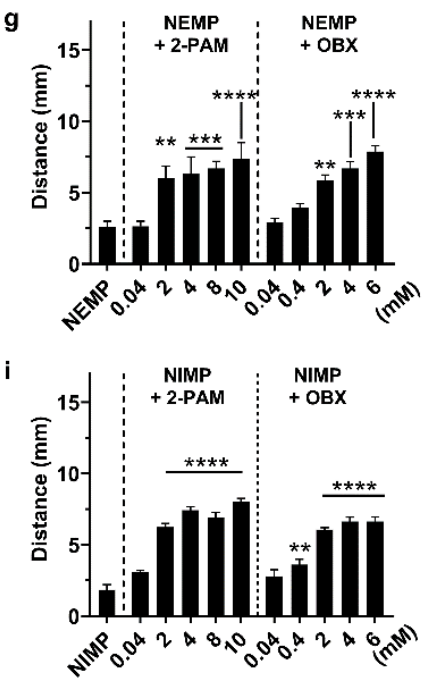

b

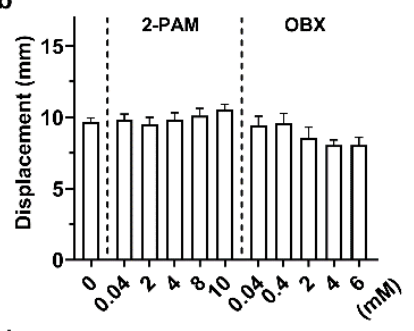

d
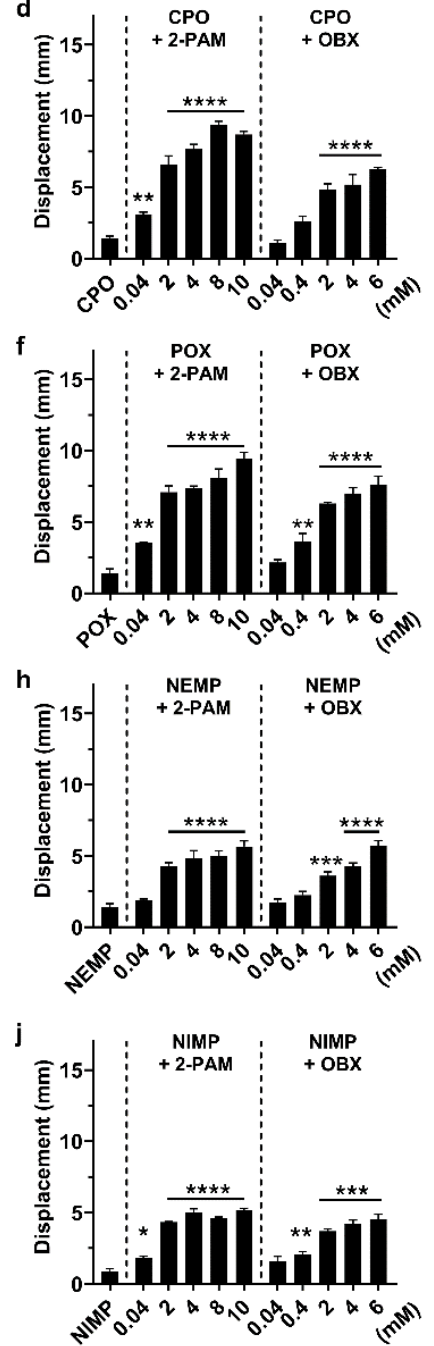

Figure S8. Determination of the minimum antidote concentration necessary to induce a significant reactivation for the distance and displacement parameters of the EFPMR test. Distance and displacement in $100 \mathrm{~ms}$ by 7 dpf larva after EFP stimulation were measured at the end of $1 \mathrm{~h}$ of exposure to selected OPs. Both parameters are reported for the control $(\mathbf{a}, \mathbf{b})$, CPO $(\mathbf{c}, \mathbf{d})$, POX $(\mathbf{e}, \mathbf{f}), \operatorname{NEMP}(\mathbf{g}, \mathbf{h})$, and NIMP $(\mathbf{i}, \mathbf{j})$ groups in the presence of a concentration range of 2-PAM or OBX. Three independent experiments were conducted with twelve larvae for each group. The data shown are the mean \pm SEM. The significances were tested using a one-way ANOVA and Dunnett's post-hoc test using the comparison with the OP treated group, ${ }^{*} \mathrm{p}<0.05,{ }^{* *} \mathrm{p}<0.01,{ }^{* * *} \mathrm{p}<0.001,{ }^{* * * *} \mathrm{p}<0.0001$. 

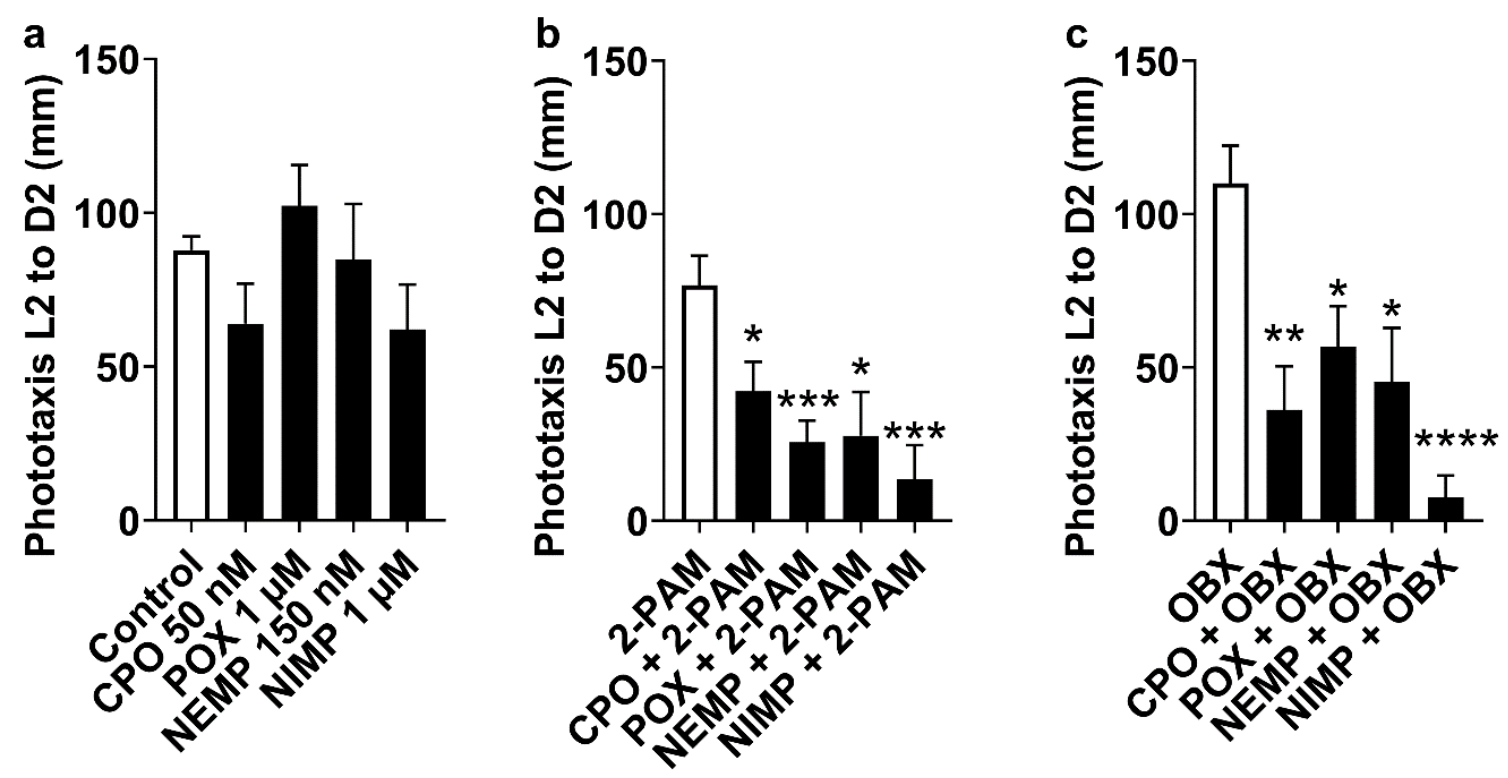

Figure S9. Phototactic response of $\mathrm{OP}$ treated larvae at $\mathrm{IC}_{50}$ and determined working concentrations without and with 2-PAM or OBX. The phototactic response, which is the ability of a larva to respond to a light transition during the VMR test, was assessed by subtracting the swimming distances covered in one minute before and one minute after during the L2-D2 transition. a, Larvae after $1 \mathrm{~h}$ of exposure to selected cholinergic OPs at their $\mathrm{IC}_{50}$, i.e. $50 \mathrm{nM}$ of CPO, $1 \mu \mathrm{M}$ of POX, $150 \mathrm{nM}$ of NEMP and $1 \mu \mathrm{M}$ of NIMP. b, Larvae after $1 \mathrm{~h}$ of exposure to selected cholinergic OPs at their working concentration in the presence of 4 $\mathrm{mM}$ of 2-PAM. These concentrations were set at $400 \mathrm{nM}$ for CPO, $15 \mu \mathrm{M}$ for POX, $400 \mathrm{nM}$ for NEMP and $6 \mu \mathrm{M}$ for NIMP in the presence of $0.1 \%$ DMSO (see the results section for criteria used to determine these working concentrations). c, Larvae after $1 \mathrm{~h}$ of exposure to cholinergic OPs at their working concentration in the presence of $4 \mathrm{mM}$ of OBX. The number of larvae enrolled in the study was $n=174$ for the control group, $n=17$ for the CPO group, and $\mathrm{n}=15$ for the POX, NEMP and NIMP groups. This number was $\mathrm{n}=72$ for the 2-PAM and OBX groups and $n=18$ for the OP plus 2-PAM and OP plus OBX groups. Three to twenty-six independent experiments were performed. The data shown are the mean \pm SEM and the significances were tested using a Brown-Forsythe ANOVA test with Dunnett's T3 multiple comparisons post-hoc test, ${ }^{*} \mathrm{p}<0.05 ; * * \mathrm{p}<0.01 ; * * * \mathrm{p}<0.001 ; * * * * \mathrm{p}<0.0001$. 


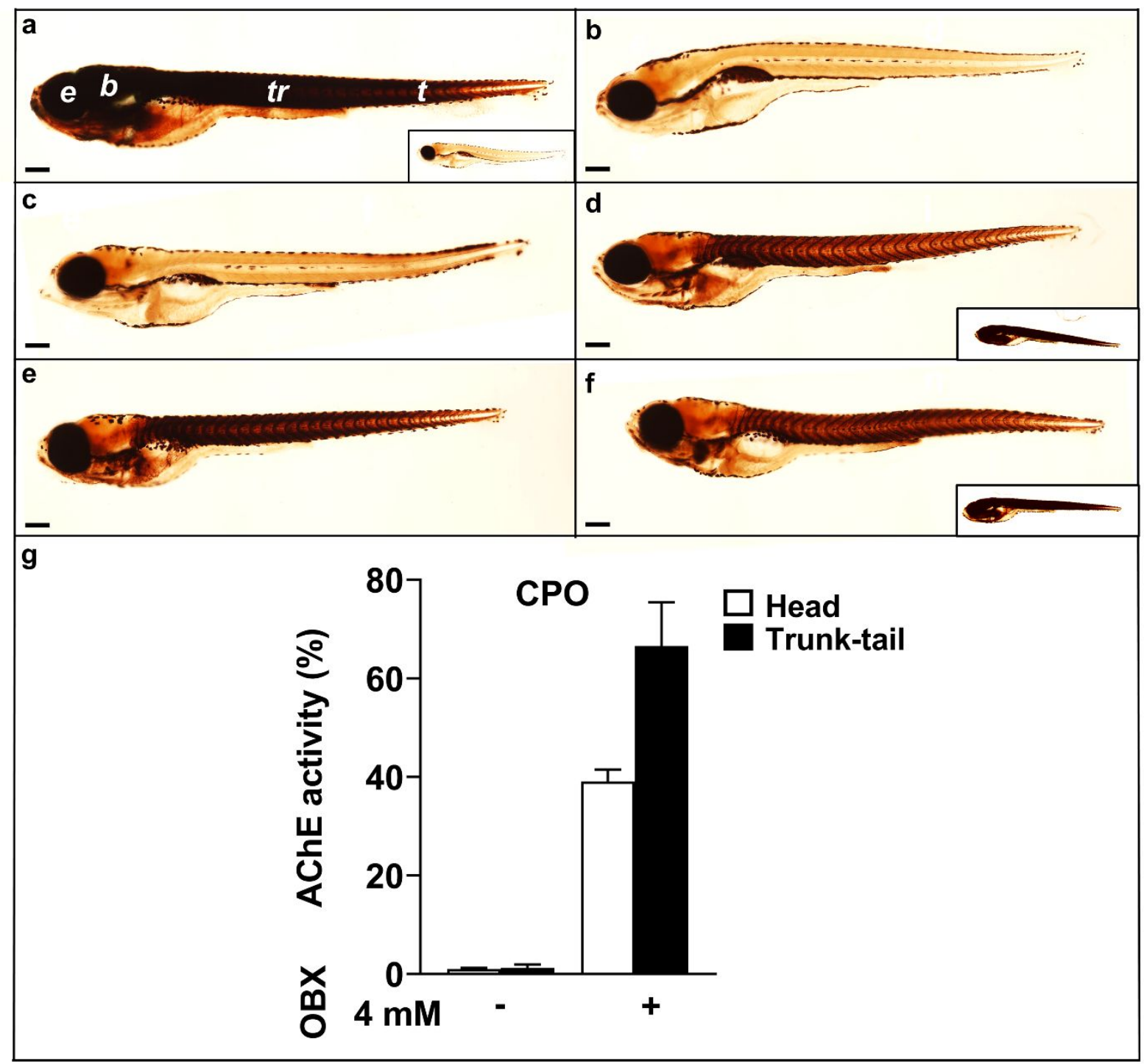

Figure S10. OBX as 2-PAM reactivate AChE activity in the PNS but not in the CNS.

Representative $7 \mathrm{dpf}$ larvae are shown in lateral view. a, Whole-mount in situ coloration of the control larva showed a dark brown precipitate revealing AChE activities in the nervous system. Exposure to $\mathrm{CPO}$ at $400 \mathrm{nM}$ (b) and POX at $15 \mu \mathrm{M}$ (c) switched off the AChE activity. In the presence of $4 \mathrm{mM}$ of oxime antidote, POX $+2-\mathrm{PAM}(\mathbf{d}), \mathrm{CPO}+\mathrm{OBX}(\mathbf{e})$ and $\mathrm{POX}+\mathrm{OBX}(\mathbf{f})$ demonstrated a marked reactivation of AChE activity in the trunk-tail. At the head level, a reactivation occurred in the nervous system attached to the oculomotor and jaw muscles but not in the brain. No staining signal was observed in larvae without $\mathrm{AChE}$ substrate (insert in a). A full AChE signal was observed in larvae with 2-PAM alone (insert in d) or with OBX alone (insert in f). Abbreviations: b, brain; e, eyes; t, tail; tr, trunk. Scale bar, $200 \mu \mathrm{m}$. g, The in vivo AChE activity was evaluated on head and trunk-tail samples after exposure with $\mathrm{CPO}$ without or with $4 \mathrm{mM}$ of $\mathrm{OBX}$. The data shown are the mean $\pm \mathrm{SD}$ of two independent experiments. 


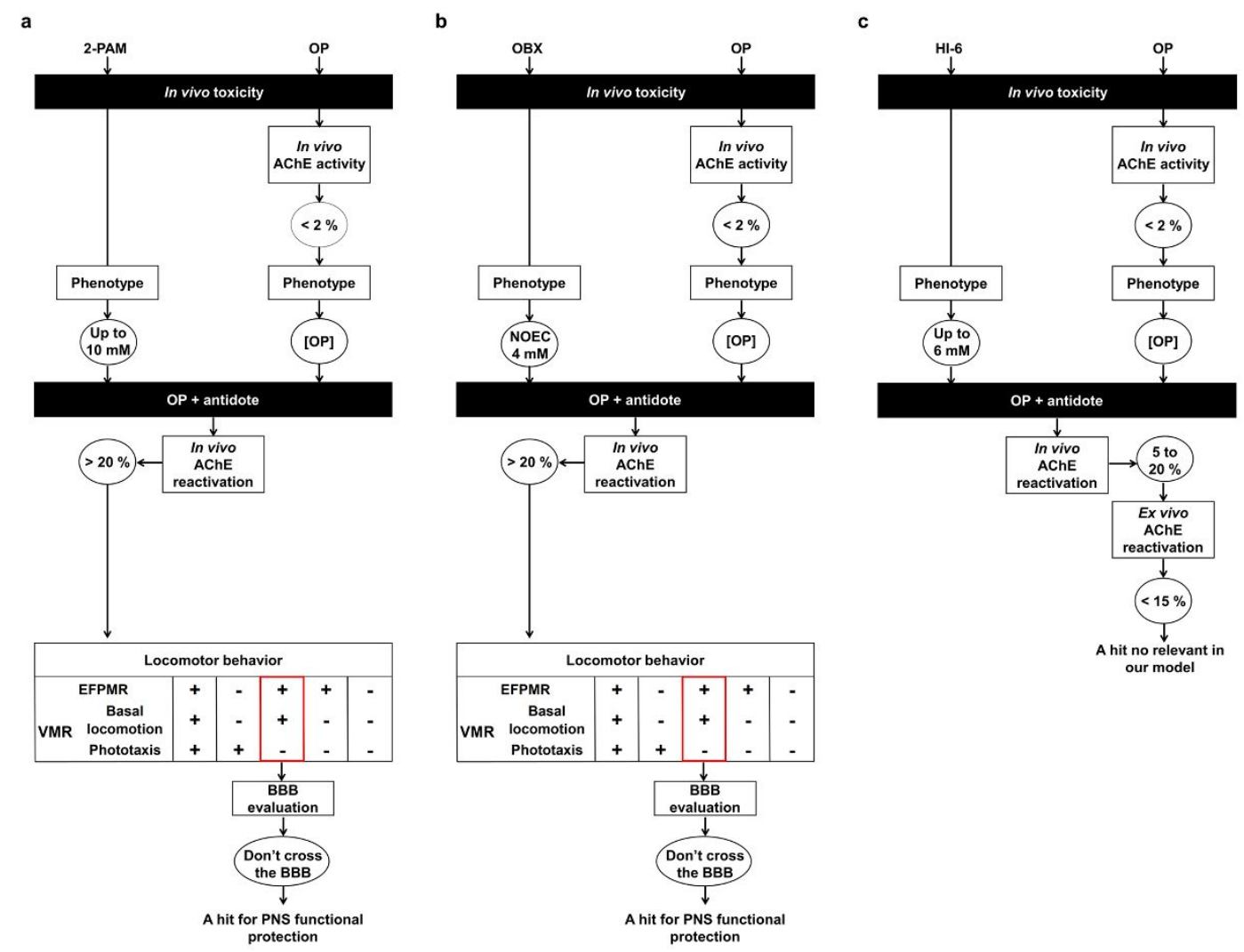

Figure S11. Antidote screening system for OP poisoning applied to 2-PAM, OBX and

HI-6. Diagram of the ZOAT steps (rectangles), describing all of the checkpoints (circles). The in vivo systemic toxicity of the antidote is evaluated on survival and locomotor behavior using the VMR and EFPMR tests, in order to determine the NOEC retained for the rest of the study. The in vivo systemic toxicity of the OP is evaluated on survival and then the in vivo AChE activity is determined. For the first OP concentration giving less than $2 \%$ of residual AChE activity, the phenotype is evaluated in the EFPMR and VMR tests in order to validate the presence of a cholinergic phenotype and to define the working OP concentration. These concentrations were $400 \mathrm{nM}$ for CPO and NEMP, $6 \mu \mathrm{M}$ for NIMP, and $15 \mu \mathrm{M}$ for POX. a, 2PAM did not induce mortality for the tested concentration range up to $10 \mathrm{mM}$. The $\mathrm{OP}+$ antidote study then revealed more than $20 \%$ of in vivo AChE activity reactivation on all of the OPs tested. Locomotor behavior showed a protection in the EFPMR test and on basal (spontaneous) locomotion (+ sign) but not on phototactic response (- sign) as evaluated with the VMR test. Therefore, 2-PAM is a hit for PNS AChE activity reactivation and functional protection. b, OBX started to somewhat alter the locomotor behavior of the larvae starting from $4 \mathrm{mM}$, which was defined as the NOEC concentration. As previously described with 2PAM, OBX is a hit for PNS AChE activity reactivation and functional protection. 2-PAM and OBX serve as a reference for the implementation of ZOAT in order to identify more effective 
treatments. c, HI-6 did not induce mortality for the tested concentration range up to $6 \mathrm{mM}$. The OP + antidote study revealed less than $20 \%$ of in vivo AChE activity reactivation on all of the OPs tested and less than $15 \%$ ex vivo AChE activity reactivation. Therefore, HI- 6 is not relevant in our model against the tested selected OPs. Additional experiments demonstrated that this oxime did not show any protection in locomotor behavior as evaluated by the EFPMR or VMR tests (data not shown).

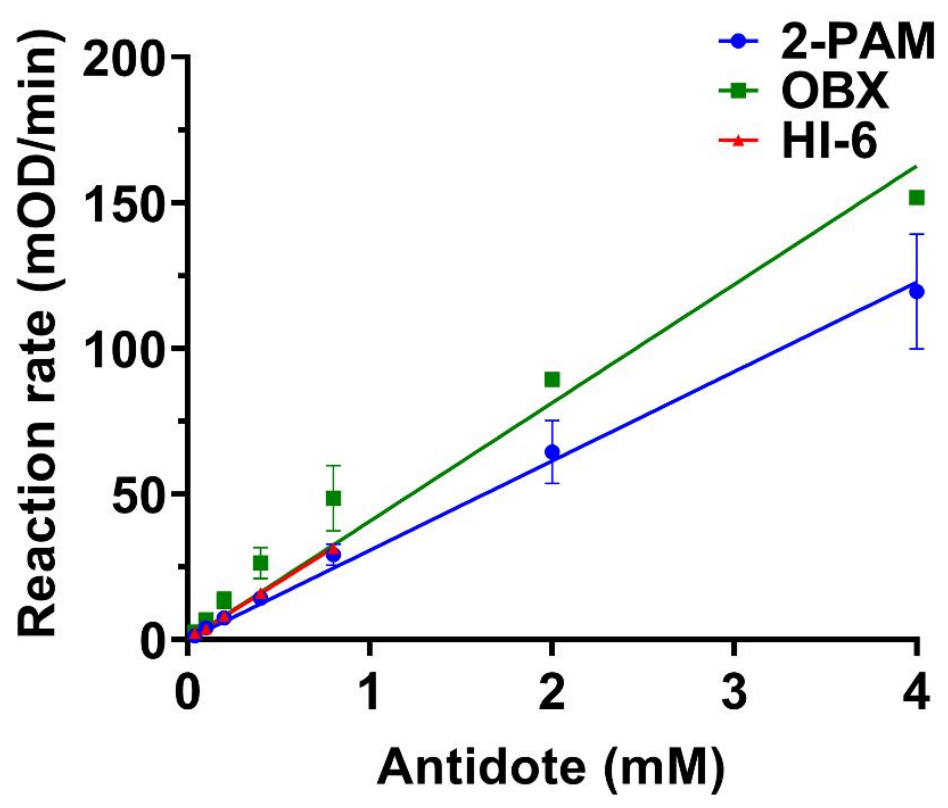

Figure S12. Oxomolysis rate according to the antidote concentration in the ex vivo AChE assay conditions. Oxomolysis is a spontaneous ATCI hydrolysis by oximes. Oxomolysis was determined in our ex vivo assays model for each tested oxime antidote within a range of concentration from $40 \mu \mathrm{M}$ to $4 \mathrm{mM}$. The oxomolysis reaction rates were determined $(\mathrm{mOD} / \mathrm{min})$ and the following linear regression equations were obtained: $\mathrm{y}=30,67 \mathrm{x}$ for 2 PAM, $y=40,65 x$ for OBX and $Y=39,45 x$ for HI- 6 . The data shown are the mean \pm SEM of three to four independent experiments for 2-PAM, three independent experiments for OBX and one for HI-6. 

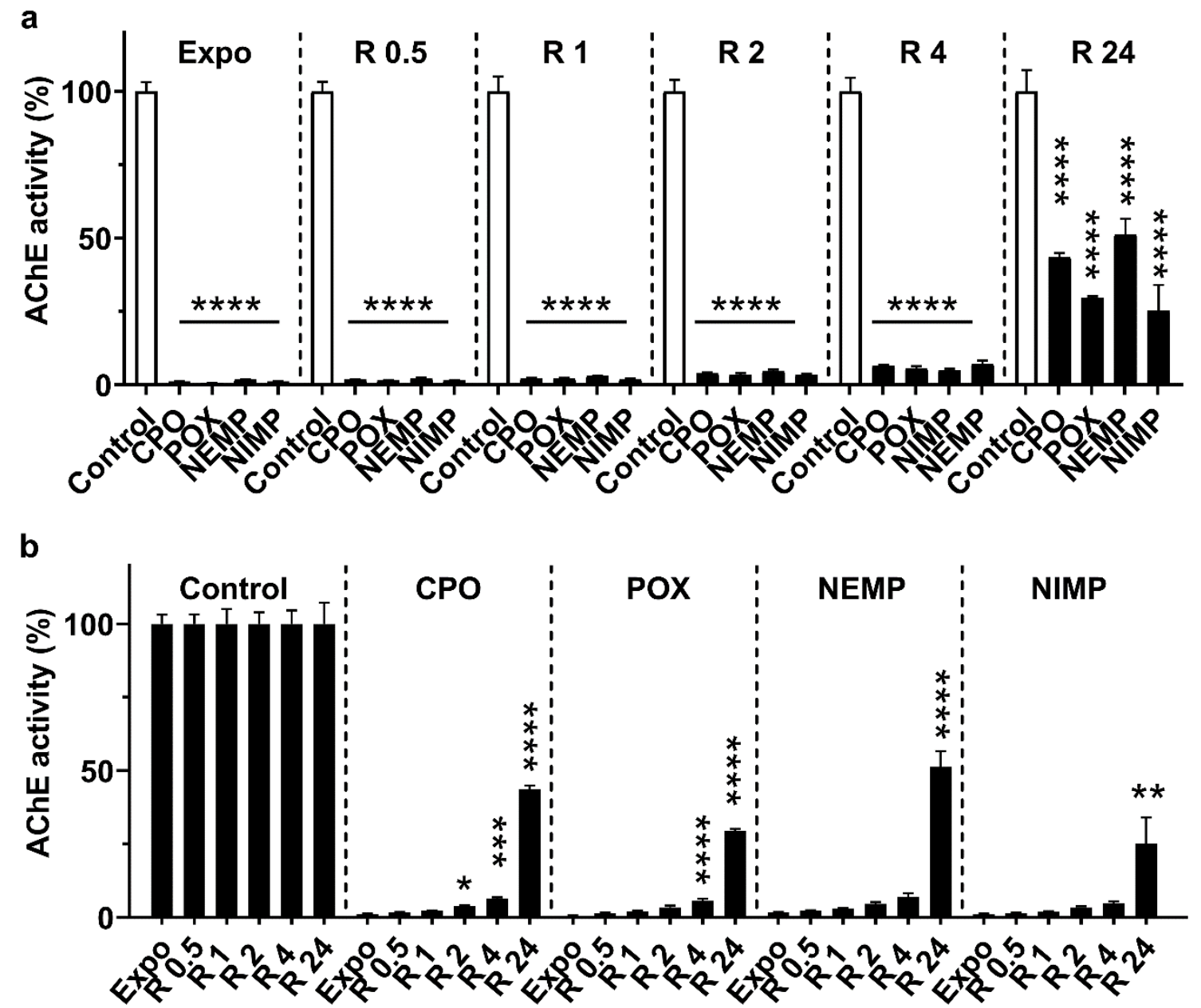

Time (h)

Figure S13. The kinetics of the spontaneous recovery of $\mathrm{AChE}$ activity after exposure to cholinergic OPs. The specific AChE activity normalized to the control activity (\%) was measured for different time points: at the end of exposure period (Expo) and $30 \mathrm{~min}$ (R 0.5), 1 h (R1), $2 \mathrm{~h}$ (R2), $4 \mathrm{~h}$ (R4) or $24 \mathrm{~h}$ (R 24) after the end of OP poisoning of the larvae. a, Comparison of the OP-inhibited AChE activity at the various time points during the spontaneous rescue. The significance was tested using a one-way ANOVA test with Dunett's post-hoc test where the OP groups were compared to the control group at each time point. $\mathbf{b}$, Characterization of the OP-inhibited AChE reactivation for each OP over the time after the exposure stop. The significance was tested using a one-way ANOVA with Dunnett's post-hoc test where the rescue time points were compared to the corresponding AChE activity at the exposure time point. The data shown are the mean \pm SEM from three independent experiments with 12 larvae for each OP exposed group, ${ }^{*} \mathrm{p}<0.05, * * \mathrm{p}<0.01, * * * \mathrm{p}<0.001$, $* * * * \mathrm{p}<0.0001$. 
a

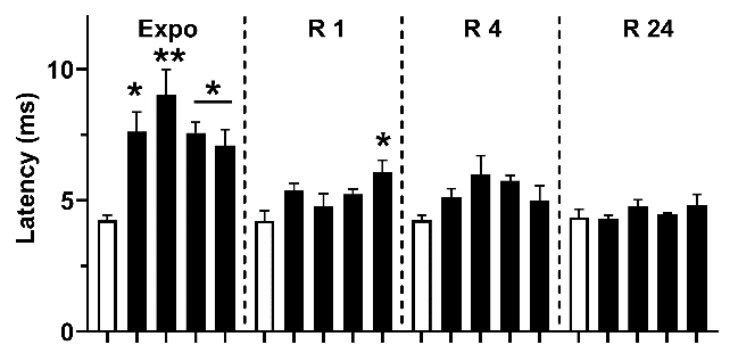

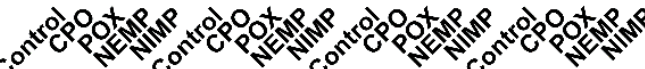

c
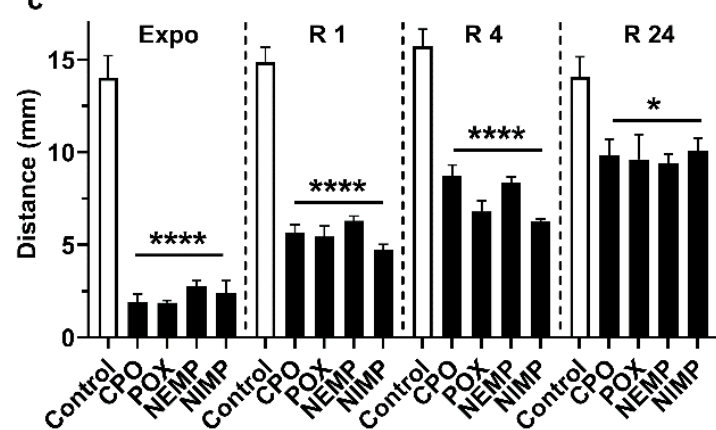
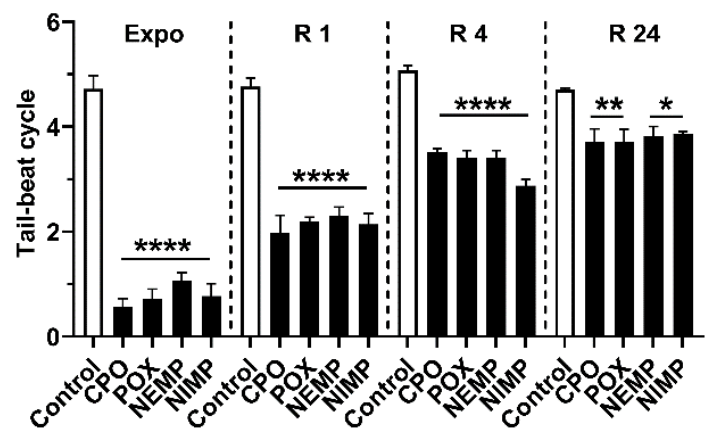

d

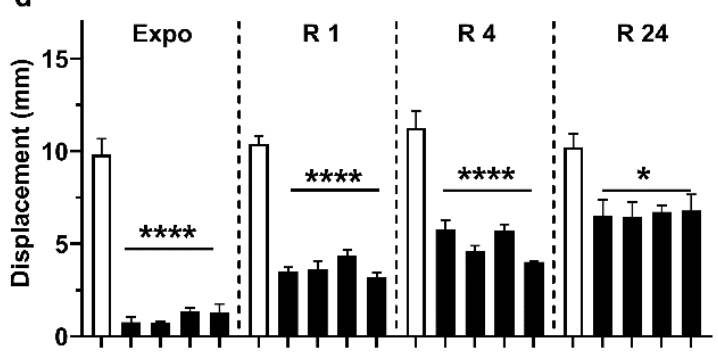

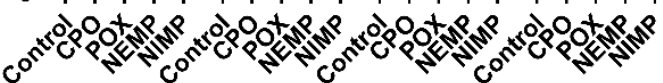

Figure S14. Spontaneous recovery of locomotor activity behavior after cholinergic OP exposure for different endpoints. Larval latency (a), tail-beat number (b), distance (c) and displacement (d) in $100 \mathrm{~ms}$ after EFP stimulation were measured at the end of the exposure period (Expo) and after $1 \mathrm{~h}(\mathrm{R} 1), 4 \mathrm{~h}(\mathrm{R} 4)$ or $24 \mathrm{~h}(\mathrm{R} 24)$ after the end of OP poisoning of the larvae. Three independent experiments were conducted with twelve larvae for each OP exposed group. The data shown are the mean \pm SEM. The significance was tested using a one-way ANOVA with Dunnett's post-hoc test where the OP group data were compared to the control at each time point, ${ }^{*} \mathrm{p}<0.05, * * \mathrm{p}<0.01,{ }^{* * *} \mathrm{p}<0.001, * * * * \mathrm{p}<0.0001$. 
a

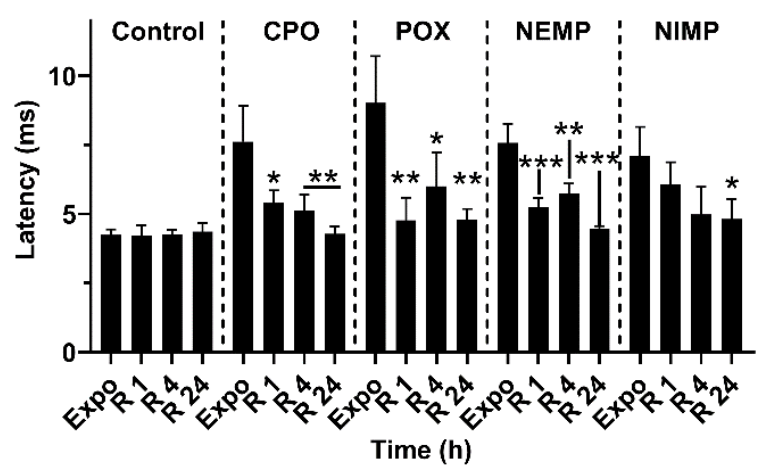

c

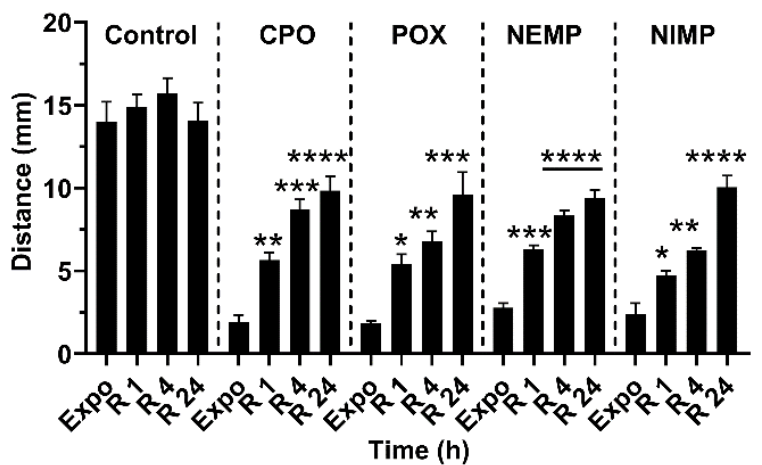

b

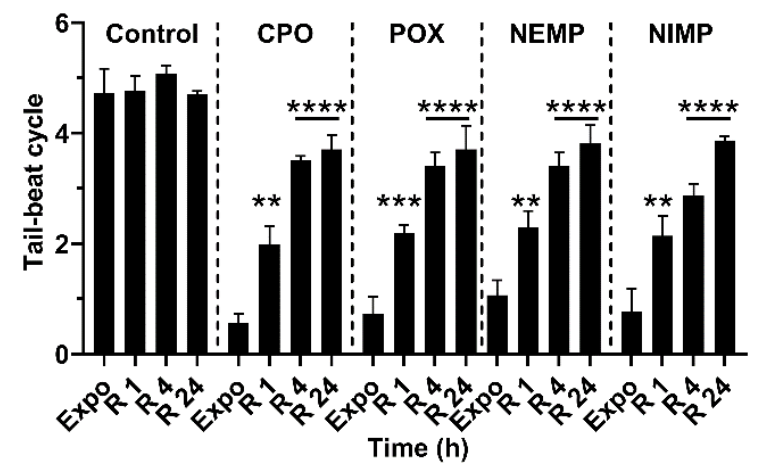

d

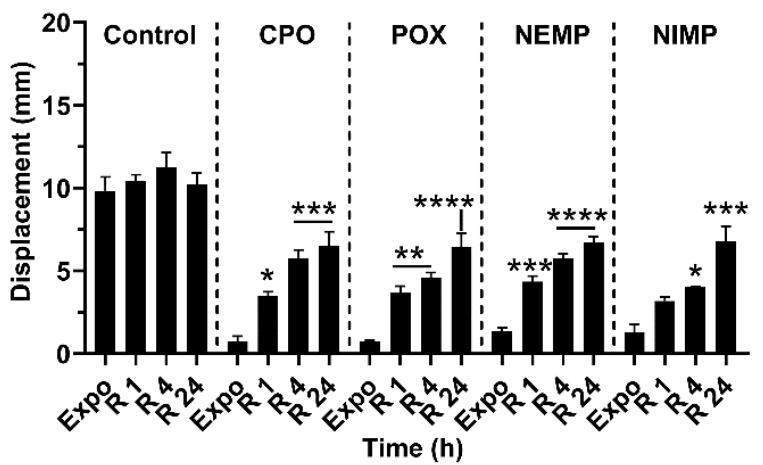

Figure S15. The kinetics of spontaneous recovery of locomotor behavior after

cholinergic OP exposure. After EFP stimulation, the latency (a), tail-beat number (b), distance (c) and displacement (d) in $100 \mathrm{~ms}$ of the OP exposed larvae at their working concentration were measured at the end of the exposure period (Expo) and after $1 \mathrm{~h}(\mathrm{R} 1), 4 \mathrm{~h}$ (R4) or $24 \mathrm{~h}$ (R24) after the end of OP poisoning of the larvae. Three independent experiments were performed with twelve larvae for each OP exposed group. The data shown are the mean \pm SEM. The significance was tested using a one-way ANOVA with Dunnett's post-hoc test where the rescue time points were compared to the control at each time point, *p $<0.05, * * \mathrm{p}<0.01, * * * \mathrm{p}<0.001, * * * * \mathrm{p}<0.0001$. 


\section{Supplementary Tables}

\begin{tabular}{|c|c|c|c|c|c|}
\hline & & CPO & PAO & NEMP & NIMP \\
\hline & {$[O P]_{0}(\mu M)$} & 0.4 & 15 & 0.4 & 6 \\
\hline \multirow{4}{*}{ in vivo } & R squared & 0.982 & 0.995 & 0.976 & 0.949 \\
\hline & $k_{\text {obs }}\left(\min ^{-1}\right)$ & $0.126+/-0.009$ & $0.229+/-0.01$ & $0.028+/-0.005$ & $0.10+/-0.014$ \\
\hline & $k_{i}\left(m^{-1} \cdot \mu M^{-1}\right)$ & 0.314 & 0.0153 & 0.0691 & 0.0172 \\
\hline & $t_{1 / 2}(\min )$ & 5.52 & 3.02 & 25.07 & 6.74 \\
\hline \multirow{4}{*}{ ex vivo } & R squared & 0.9898 & 0.9912 & 0.9963 & 0.9756 \\
\hline & $k_{\text {obs }}\left(\min ^{-1}\right)$ & $0.49+/-0.04$ & $0.44+/-0.029$ & $0.60+/-0.04$ & $0.31+/-0.024$ \\
\hline & $k_{i}\left(\min ^{-1} \cdot \mu M^{-1}\right)$ & 1.23 & 0.0296 & 1.51 & 0.0511 \\
\hline & $t_{1 / 2}(\min )$ & 1.405 & 1.56 & 1.15 & 2.26 \\
\hline
\end{tabular}

Table S1. Zebrafish AChE inhibition constants determined in vivo and ex vivo after exposure to CPO, POX, NEMP and NIMP. The data used are extracted from Figures $1 \mathrm{c}, \mathrm{d}$. The in vivo procedure consisted in exposing the larvae with a range of concentration of the various OPs selected and then measuring the AChE activity. In the case of ex vivo determination, the AChE enzymatic activity was measured from an extract of biological larval material incubated ex vivo at the same concentration range of the selected OPs. 


\begin{tabular}{|c|c|c|c|c|}
\hline & \multicolumn{2}{|c|}{ Antidote } & \multirow{2}{*}{$\begin{array}{c}\text { in vivo } \\
3.3 \pm 1.4 \\
22.9 \pm 4.3\end{array}$} & \multirow{2}{*}{$\begin{array}{c}\text { ex vivo } \\
23.7 \pm 3.2\end{array}$} \\
\hline \multirow{3}{*}{ CPO } & 2-PAM & $\begin{array}{c}40 \mu \mathrm{M} \\
2 \mathrm{mM}\end{array}$ & & \\
\hline & OBX & $\begin{array}{c}40 \mu \mathrm{M} \\
2 \mathrm{mM}\end{array}$ & $\begin{array}{c}1.7 \pm 0.7 \\
41.7 \pm 5.8\end{array}$ & $42.09 \pm 3.8$ \\
\hline & HI-6 & $\begin{array}{c}100 \mu \mathrm{M} \\
2 \mathrm{mM}\end{array}$ & $4 \pm 2.2$ & $4.6 \pm 0.8$ \\
\hline \multirow{3}{*}{ POX } & 2-PAM & $\begin{array}{c}40 \mu \mathrm{M} \\
2 \mathrm{mM}\end{array}$ & $\begin{array}{c}1.7 \pm 1 \\
20.3 \pm 3.8\end{array}$ & $22.6 \pm 2.7$ \\
\hline & OBX & $\begin{array}{c}40 \mu \mathrm{M} \\
2 \mathrm{mM}\end{array}$ & $\begin{array}{l}1.3 \pm 0.6 \\
42.7 \pm 2\end{array}$ & $32.08 \pm 0.8$ \\
\hline & HI-6 & $\begin{array}{c}100 \mu \mathrm{M} \\
2 \mathrm{mM}\end{array}$ & $3.3 \pm 0.7$ & $2.3 \pm 0.2$ \\
\hline \multirow{3}{*}{ NEMP } & 2-PAM & $\begin{array}{c}40 \mu \mathrm{M} \\
6 \mathrm{mM}\end{array}$ & $\begin{array}{c}0.98 \pm 0.3 \\
44 \pm 1.3\end{array}$ & $45.1 \pm 0.9$ \\
\hline & OBX & $\begin{array}{c}40 \mu \mathrm{M} \\
6 \mathrm{mM}\end{array}$ & $\begin{array}{c}0.64 \pm 0.5 \\
29.15 \pm 3.7\end{array}$ & $53.3 \pm 6.7$ \\
\hline & HI-6 & $\begin{array}{c}100 \mu \mathrm{M} \\
6 \mathrm{mM}\end{array}$ & $9.2 \pm 6.2$ & $2.8 \pm 0.3$ \\
\hline \multirow{3}{*}{ NIMP } & 2-PAM & $\begin{array}{c}40 \mu \mathrm{M} \\
6 \mathrm{mM}\end{array}$ & $\begin{array}{c}1.36 \pm 1.1 \\
52.4 \pm 10.1\end{array}$ & $42.8 \pm 0.3$ \\
\hline & OBX & $\begin{array}{c}40 \mu \mathrm{M} \\
6 \mathrm{mM}\end{array}$ & $\begin{array}{c}1.5 \pm 0.1 \\
18.9 \pm 2.2\end{array}$ & $35.8 \pm 1.9$ \\
\hline & HI-6 & $\begin{array}{c}100 \mu \mathrm{M} \\
6 \mathrm{mM}\end{array}$ & $6.6 \pm 1.4$ & $3.96 \pm 0.2$ \\
\hline
\end{tabular}

Table S2. Percentage of AChE activity reactivation by oximes determined in vivo and ex vivo. The data presented were extracted from those presented in Fig. 2 and give an indication of the ratio needed in terms of the oxime concentration to obtain a comparable percentage of reactivation of $\mathrm{AChE}$ activity between in vivo and ex vivo exposures. 
Two-ways ANOVA results for sources of variation

\begin{tabular}{cccc}
\hline Control/OP & ${ }^{* * * *}$ & Control/OP & ${ }^{* * * *}$ \\
\hline [2-PAM] & ${ }^{* * * *}$ & {$[\mathrm{OBX}]$} & ${ }^{* * * *}$ \\
\hline Interaction & ${ }^{* * * *}$ & Interaction & ${ }^{* * * *}$ \\
\hline
\end{tabular}

Dunnett's multiple comparisons test

\begin{tabular}{|c|c|c|c|c|c|}
\hline \multicolumn{2}{|c|}{ Antidotes } & CPO & POX & NEMP & NIMP \\
\hline \multirow{6}{*}{ 2-PAM (mM) } & 0 & $\star \star * \star *$ & $\star * * *$ & $\star * * *$ & 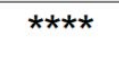 \\
\hline & 0.04 & $\star \star \star \star ~$ & $\star \star \star \star ~$ & $\star \star \star \star *$ & $\star \star \star \star ~$ \\
\hline & 2 & $\star \star \star *$ & $\star *$ & $\star * * *$ & $\star \star \star \star ~$ \\
\hline & 4 & ** & $* * *$ & $* * * *$ & $\star * * *$ \\
\hline & 8 & ns & ** & $\star * * *$ & $\star \star \star \star *$ \\
\hline & 10 & ns & ns & $\star * * *$ & 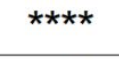 \\
\hline \multirow{6}{*}{ OBX (mM) } & 0 & $\star \star \star \star$ & $\star \star \star \star$ & $\star * * *$ & $\star \star \star \star$ \\
\hline & 0.04 & 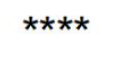 & 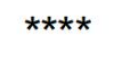 & $\star * * *$ & 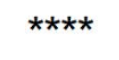 \\
\hline & 0.4 & $\star \star \star \star *$ & $\star * * *$ & $\star * * *$ & $\star \star \star \star *$ \\
\hline & 2 & $\star * \star * *$ & ** & $* * * *$ & 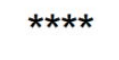 \\
\hline & 4 & *** & ns & $\star * * *$ & $\star \star \star \star *$ \\
\hline & 6 & ns & ns & $\star * * *$ & $\star \star \star \star *$ \\
\hline
\end{tabular}

Table S3. Statistical analysis of the effect of a range of 2-PAM or OBX concentrations on the distance travelled by the larvae after OP exposure and EFP stimulation. Statistical data were obtained from the results presented in Fig. 3c,d. Each OP plus antidote tested condition was compared to an equivalent antidote concentration in the absence of OP. Not significant (ns), $* * \mathrm{p}<0.01, * * * \mathrm{p}<0.001$ 
Two-ways ANOVA results for sources of variation

\begin{tabular}{cccc}
\hline Control/OP & $* * \star *$ & Control/OP & $* \star * *$ \\
\hline [2-PAM] & $* * * *$ & [OBX] & $* \star * *$ \\
\hline Interaction & $* * * *$ & Interaction & $* \star * *$ \\
\hline
\end{tabular}

Dunnett's multiple comparisons test

\begin{tabular}{|c|c|c|c|c|c|}
\hline \multicolumn{2}{|c|}{ Antidote } & CPO & POX & NEMP & NIMP \\
\hline \multirow{6}{*}{ 2-PAM (mM) } & 0 & 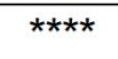 & $\star \star \star \star *$ & $* * * *$ & $\star * * *$ \\
\hline & 0.04 & 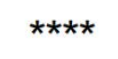 & $* * * *$ & $\star \star \star * *$ & 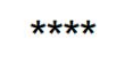 \\
\hline & 2 & $\star * * *$ & ** & $\star \star \star \star *$ & $\star * \star *$ \\
\hline & 4 & $* * *$ & ** & $\star * * *$ & $\star * * *$ \\
\hline & 8 & ns & ns & $\star \star * *$ & 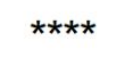 \\
\hline & 10 & $\star * *$ & ns & $* * * *$ & $\star * * *$ \\
\hline \multirow{6}{*}{ OBX (mM) } & 0 & 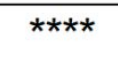 & $\star * \star * *$ & 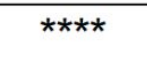 & 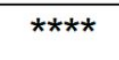 \\
\hline & 0.04 & 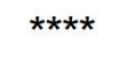 & $\star * * *$ & $\star * \star *$ & $\star \star \star \star *$ \\
\hline & 0.4 & 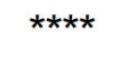 & $\star \star * * *$ & $* * * *$ & $\star \star \star *$ \\
\hline & 2 & $* * *$ & ns & $\star \star \star \star *$ & $\star * * *$ \\
\hline & 4 & ** & ns & $* * *$ & 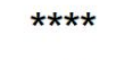 \\
\hline & 6 & * & ns & ** & $\star * * *$ \\
\hline
\end{tabular}

Table S4. Statistical analysis of the effect of a range of 2-PAM or OBX concentrations on the displacement travelled by the larvae after OP exposure and EFP stimulation.

Statistical data were obtained from the results presented in Figure S7. Each OP plus antidote tested condition was compared to an equivalent antidote concentration in the absence of OP. Not significant (ns), ${ }^{* *} \mathrm{p}<0.01, * * * \mathrm{p}<0.001, * * * * \mathrm{p}<0.0001$ 
Two-ways ANOVA results for sources of variation

\begin{tabular}{cccc}
\hline Control/OP & ${ }^{* * * *}$ & Control/OP & ${ }^{* * *}$ \\
\hline$[2-\mathrm{PAM}]$ & ${ }^{* * * *}$ & {$[\mathrm{OBX}]$} & $\mathrm{ns}$ \\
\hline Interaction & $\mathrm{ns}$ & Interaction & ${ }^{* * * *}$
\end{tabular}

Dunnett's multiple comparisons test

\begin{tabular}{|c|c|c|c|c|c|}
\hline Antidote & & CPO & POX & NEMP & NIMP \\
\hline \multirow{4}{*}{ 2-PAM (mM) } & 0 & $* \star * *$ & $* * * *$ & 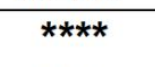 & $\star \star \star \star *$ \\
\hline & 2 & ** & $* * * *$ & $* * * *$ & $\star * * *$ \\
\hline & 4 & $* * * *$ & $* * * *$ & $\star * * *$ & $\star * * *$ \\
\hline & 8 & $* * * *$ & $* * * *$ & $* * * *$ & $\star * * *$ \\
\hline \multirow{4}{*}{ OBX (mM) } & 0 & $\star \star * * *$ & $\star * * *$ & $\star \star \star * *$ & $\star \star * * *$ \\
\hline & 0.4 & $* * * *$ & $\star \star \star * *$ & $* * * *$ & $\star * * *$ \\
\hline & 2 & $* * * *$ & $* * * *$ & $\star * * * *$ & $* * * *$ \\
\hline & 4 & $* * *$ & ** & * & $\star * * *$ \\
\hline
\end{tabular}

Table S5. Statistical analysis of the effect of a range of 2-PAM or OBX concentrations on the distance travelled by the larva during the D2 phase of the VMR test protocol.

Statistical data were obtained from the results presented in Fig. 4a,b. Not significant (ns), ** p $<0.01, * * * \mathrm{p}<0.001, * * * * \mathrm{p}<0.0001$.

\begin{tabular}{cccccccc}
\cline { 2 - 8 } & $\begin{array}{c}\text { Molecular } \\
\text { weight } \\
(\mathbf{g} / \mathbf{m o l})\end{array}$ & $\begin{array}{c}\text { Density } \\
\text { at } \mathbf{2 5}^{\circ} \mathbf{C} \\
\left(\mathbf{g} / \mathbf{c m}^{3}\right)\end{array}$ & $\begin{array}{c}\text { Boiling } \\
\left({ }^{\circ} \mathbf{C}\right)\end{array}$ & $\begin{array}{c}\text { Melting } \\
\text { point } \\
\left({ }^{\circ} \mathbf{C}\right)\end{array}$ & $\begin{array}{c}\text { Vapor } \\
\text { pressure } \\
\text { at } \mathbf{2 0 - 2 5} 5^{\circ} \mathbf{C} \\
(\mathbf{m m ~ H g})\end{array}$ & $\begin{array}{c}\text { Water } \\
\text { solubility } \\
\mathbf{2 0 - 2 5} \mathbf{~} \mathbf{C}\end{array}$ & Log $\mathbf{P}$ \\
\hline CPO & 334.5 & 1.4 & na & 41.3 & na & na & $3.37^{*}$ \\
\hline POX & 275.19 & 1.27 & 170 & 300 & $1.1 \times 10^{-6}$ & 0.364 & 1.98 \\
\hline NEMP & 245.17 & na & $125-127$ & na & na & na & $1.64^{*}$ \\
\hline NIMP & 259.2 & na & 136 & na & na & na & $2^{*}$ \\
\hline
\end{tabular}

Table S6. Physico-chemical properties of the OPs selected for the study. Sources:

Costanzi, S. et al., ACS Chem. Neurosci. 9, 873-885 (2018). PubChem

(https://pubchem.ncbi.nlm.nih.gov/) and product sheets. *Calculated value using

Molinspiration Cheminformatics tools (www.molinspiration.com/cgi-bin/properties). Non available (na). 


\begin{tabular}{cccc}
\hline $\begin{array}{c}\text { Antidote } \\
\text { concentration (mM) }\end{array}$ & 2-PAM & OBX & HI-6 \\
\hline 0.04 & 0.424 & 0.690 & 0.752 \\
0.1 & 1.333 & 1.979 & 1.246 \\
0.2 & 2.861 & 4.09 & 2.846 \\
0.4 & 6.363 & 8.011 & 6.088 \\
0.8 & 13.344 & 14.257 & 13.018 \\
2 & 33.254 & 21.392 & nd \\
4 & 51.767 & 25.615 & nd \\
\hline
\end{tabular}

Table S7. Percentage of oximolysis according to the antidote concentration in the ex vivo AChE assay conditions. The linearity relationship between the oxime concentration and the rate of spontaneous ATCI hydrolysis is indicated in Figure S12. The optic density velocity ratio $(\mathrm{mOD} / \mathrm{min})$ measured in the specified condition both with and without biological extract supernatant, respectively. Not determined (nd). 